\title{
Design of Adaptive Fuzzy PID Controller for Electropneumatic System
}

\author{
Krasimir Ormandzhiev ${ }^{1}$ and Stanimir Yordanov $^{2}$ \\ ${ }^{1}$ Technical University of Gabrovo, Department of Power Engineering, 4 H. Dimitar str., 5300 \\ Gabrovo, Bulgaria \\ ${ }^{2}$ Technical University of Gabrovo, Department of Automation, Information and Control Systems, 4 \\ H. Dimitar str., 5300 Gabrovo, Bulgaria
}

\begin{abstract}
The purpose of the study is to develop an adaptive electropneumatic automatic system based on the classical PID controller using modern technology for controlling like fuzzy controlling. The need of an adaptive setting occurred because of the fact that the classic controller has high sensitivity towards interferences with the main signal and the need for the parameters to be regulated often and be done by hand. Another reason is the inability to provide optimal parameters for the controller for nonlinear processes and changes of the parameters in time. In this article the work of electropneumatic system with linear actuator, is examined. A mathematical model describing the dynamics of the processes, is developed. An adaptive fuzzy PID controller with variable coefficients is synthesized. The system is studied in the environment of Matlab Simulink. The transient processes in the system are compared to processes where the classical PID controller. The results are presented in graphical form.
\end{abstract}

Key words: adaptive fuzzy PID control, electropneumatic system

\section{Introduction}

The pneumatic drive systems used in industrial production are characterized by relatively simple construction, easy maintenance and exploitation, high speed, good reliability, functional flexibility and low cost. They can be successfully used to work in aggressive, explosive and flammable environments.

The development of new materials, technologies of construction and production determine the increase of the qualities and the constant expansion of the nomenclature and the areas of application of the automatic pneumatic devices and systems. The development and intensive implementation of electronic and microprocessor technology in automated equipment and technological processes contributes to the development of pneumatic systems and their transformation into intelligent electropneumatic systems.

All of the above indicate the need to study the operation of pneumatic tracking systems, especially in dynamic modes. Until now, most of the developed mathematical models of electropneumatic systems are mainly linear $[4,5]$, which does not allow adequate obtaining of the processes occurring in real systems. In $[1,3]$ a nonlinear mathematical model of an electropneumatic drive system for reverse translational movement of the actuator, is 
developed, and the ongoing dynamic processes in different operating modes, are studied. The nature of the force of dry friction, is studied in [2]. When complex objects of this type operating in non-stationary conditions are controlled, widely used are adaptive controllers, which apply PI or PID control laws. As a rule, the Ziegler-Nichols is most often method used for tuning the regulators [12]. This method requires the object of control to be leaded into self-oscillating mode by changing the gain $\mathrm{K}_{\mathrm{r}}$ in a regulator, implementing P-control law. A large number of technological processes in working conditions do not allow self-oscillating mode. Thus, the problem of finding the optimal method of adaptation remains open. At the same time, fuzzy models and control algorithms have been widely used recently $[13,14]$. It is known that fuzzy control is based not only on the use of analytical or theoretical models, but also on the practical application of the knowledge of qualified professionals, given as a form of language bases of rules. Fuzzy control is effective in cases of nondeterminism of the parameters of the objects, when there is some experience of experts in the control and tuning of an automated control system (ACS). Based on the above, the task of creating a method for adapting a PID controller that implements the experience of the tuners becomes relevant.

The aim of the article is to develop a model for the Fuzzy PID controller, which determines the optimal settings of the PID controller for its adaptation to the controlled object, and its testing in a MATLAB Simulink environment.

\section{Mathematical model}

Figure 1 shows a diagram of an electropneumatic drive system with a rotary actuator.

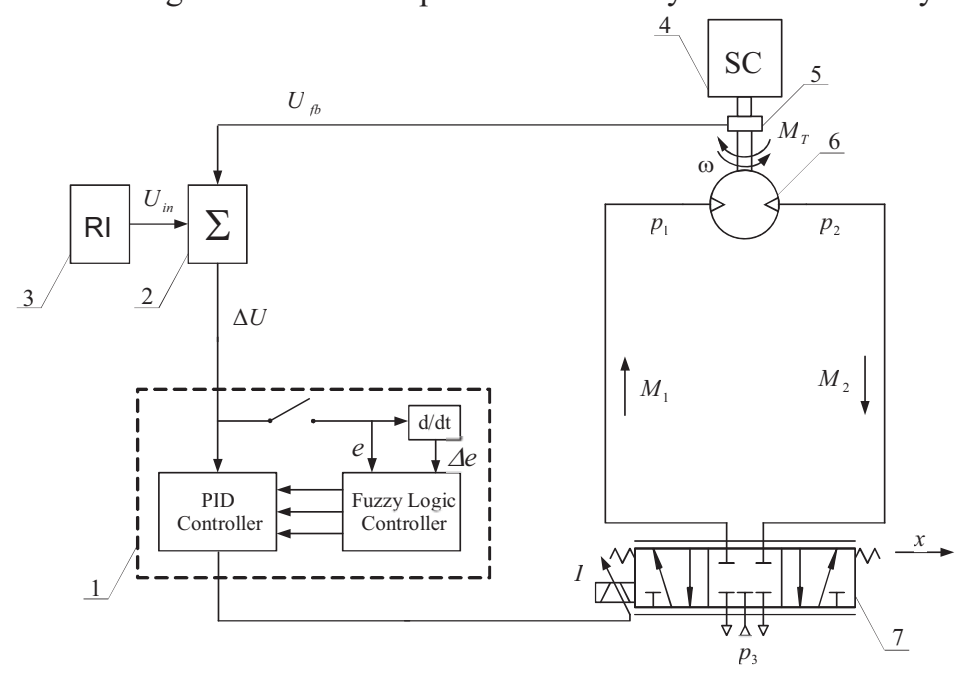

Fig. 1. Diagram of the electropneumatic tracking system.

1 - automatic controller; 2 - summing device; 3 - reference or input device; 4 - subject for control (SC); 5 - tachogenerator; 6 - pneumatic motor; 7 - electropneumatic servovalve;

1. Equation of the electronic PID controller:

where:

$$
U=k\left(\Delta U+\frac{1}{T_{I}} \int_{0}^{t} \Delta U d t+T_{D} \frac{d \Delta U}{d t}\right)
$$

$U$ - output voltage of the regulator, [V];

$\Delta U$ - input voltage coming from the summing device, [V];

$k$ - gain coefficient of the controller;

$T_{I}, T_{D^{-}}$- time-constants of integration and differentiation of the controller, [s];

3.2. Equation of the electromechanical converter of the servovalve: 


$$
T_{u} \frac{d I}{d t}+I=k_{u} U
$$

where: $T_{u},-$ time constant of the electromechanical converter, [s];

$k_{u}$-gain coefficient of the electromechanical converter, $[\mathrm{m} / \mathrm{V}]$;

$I$ - output current from the electromechanical converter, [A];

3. Equation for spool position the spool of the servovalve:

Based on the logarithmic frequency characteristics of a servovalve type 5/3-WegeServoventile, manufactured by Herion [6], its operation in dynamic mode can be described approximately by a second-order differential equation [1]:

$$
T_{v}^{2} \frac{d^{2} x}{d t^{2}}+2 \xi_{v} T_{v} \frac{d x}{d t}+x=k_{I} I
$$

where: $T_{v}$ - time constant, [s], $\xi_{v}$-damping factor, $k_{I}$-servovalve gain [m/A].

4. Equation of the summing device:

$$
\Delta U=U_{i n}-U_{f b}
$$

where: $U_{\text {in }}$ - input voltage, [V]; $U_{f b}-$ feedback voltage, [V].

5. Feedback equation:

$$
U_{f b}=k_{f b} \omega
$$

where: $k_{f b}$ - feedback gain coefficient, [V.s/rad].

6. Equation for the spool position of the pneumatic motor shaft:

$$
J \frac{d \omega}{d t}+k_{T} \omega+M_{F}=w\left(p_{1}-p_{2}\right)-M_{T}(t)
$$

where: $\omega$ - angular speed of the shaft of hydraulic motor, $[\mathrm{rad} / \mathrm{s}]$;

$w$-typical (specific) volume of the hydraulic motor, $\left[\mathrm{m}^{3} / \mathrm{rad}\right]$;

$p_{1}, p_{2}$ - pressure on the left (right) chamber of hydraulic motor, $[\mathrm{Pa}]$;

$J$ - reduced torque of inertia towards the shaft of hydraulic motor, [kg. $\left.\mathrm{m}^{2}\right]$;

$k_{T}$ - coefficient of the hydraulic friction, [N.m.s/rad];

$M_{F}$ - torque of dry friction (fig. 2), [N.m]; $M_{T}(t)$ - loading torque, [N.m].

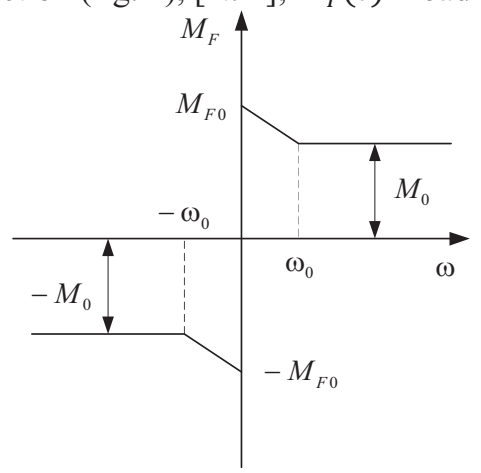

Fig. 2. Characteristic of the torque of dry friction.

The mathematical description of the torque of dry friction $M_{T 0}$ has the form:

$$
M_{F}=\left\{\begin{array}{c}
\left(M_{T 0}-k_{T c} \omega\right) \operatorname{sign}(\omega), \quad 0<|\omega| \leq \omega_{0} \\
M_{0} \operatorname{sign}(\omega), \quad \omega_{0}<|\omega| \\
M_{T 0} \operatorname{sign}\left(\frac{d \omega}{d t}\right), \quad \omega=0
\end{array}\right.
$$

7. The equations for incoming and outgoing mass flow to and from the pneumatic motor, are as follows:

$$
\begin{aligned}
& M_{1}=\frac{1}{R T_{1}}\left[p_{1} w \omega+V_{10} \frac{d p_{1}}{d t} \operatorname{sign}(\omega)\right] \\
& M_{2}=\frac{1}{R T_{2}}\left[p_{2} w \omega-V_{20} \frac{d p_{2}}{d t} \operatorname{sign}(\omega)\right]
\end{aligned}
$$


where: $M_{1}, M_{2}$ - mass flow-rates; $\mathrm{R}$ - gas constant, [ $\mathrm{J} \mathrm{mol}^{-1} \mathrm{~K}^{-1}$;

$T_{1}, T_{2}$ - absolute air temperatures on the left and right side of the pneumatic motor, $[\mathrm{K}]$;

$V_{10}, V_{20}$ - volumes on the left and right sides of the pneumatic motor, $\left[\mathrm{m}^{3}\right]$;

$$
V_{10}=V_{T 1}+0.5 q_{M} ; V_{20}=V_{T 2}+0.5 q_{M} \text {. }
$$

$V_{T 1}, V_{T 2}-$ volumes of the left and right pipelines connecting the servovalve and the pneumatic motor, $\left[\mathrm{m}^{3}\right]$;

$q_{M} \quad$ - operating volume of the pneumatic motor, $q_{M}=2 \pi \mathrm{w},\left[\mathrm{m}^{3}\right]$.

8. The equations for the mass flow-rates passing through the servovalve, are as follows:

- for $x \geq 0$

- for $x<0$

$$
\begin{aligned}
& M_{1}=\mu_{1} \pi d x p_{3} \sqrt{\frac{2 k}{R T_{1}(k-1)}\left[\left(\frac{p_{1}}{p_{3}}\right)^{\frac{2}{k}}-\left(\frac{p_{1}}{p_{3}}\right)^{\frac{k+1}{k}}\right]} \\
& M_{2}=\mu_{2} \pi d x p_{2} \sqrt{\frac{2 k}{R T_{2}(k-1)}\left[\left(\frac{p_{a}}{p_{2}}\right)^{\frac{2}{k}}-\left(\frac{p_{a}}{p_{2}}\right)^{\frac{k+1}{k}}\right]}
\end{aligned}
$$

$$
\begin{aligned}
& M_{1}=\mu_{1} \pi d x p_{1} \sqrt{\frac{2 k}{R T_{1}(k-1)}\left[\left(\frac{p_{a}}{p_{1}}\right)^{\frac{2}{k}}-\left(\frac{p_{a}}{p_{1}}\right)^{\frac{k+1}{k}}\right]} \\
& M_{2}=\mu_{2} \pi d x p_{3} \sqrt{\frac{2 k}{R T_{2}(k-1)}\left[\left(\frac{p_{2}}{p_{3}}\right)^{\frac{2}{k}}-\left(\frac{p_{2}}{p_{3}}\right)^{\frac{k+1}{k}}\right]}
\end{aligned}
$$

where: $\mu_{1}, \mu_{2}$ - flow coefficients; $d$-diameter of the servovalve spool, [m];

$p_{3}$ - supply pressure, $[\mathrm{Pa}] ; \mathrm{x}$ - spool position the spool to the servovalve;

$\mathrm{k}$ - adiabatic index $(\mathrm{k}=1,4)$.

Figure 3 shows the Simulink model of the system

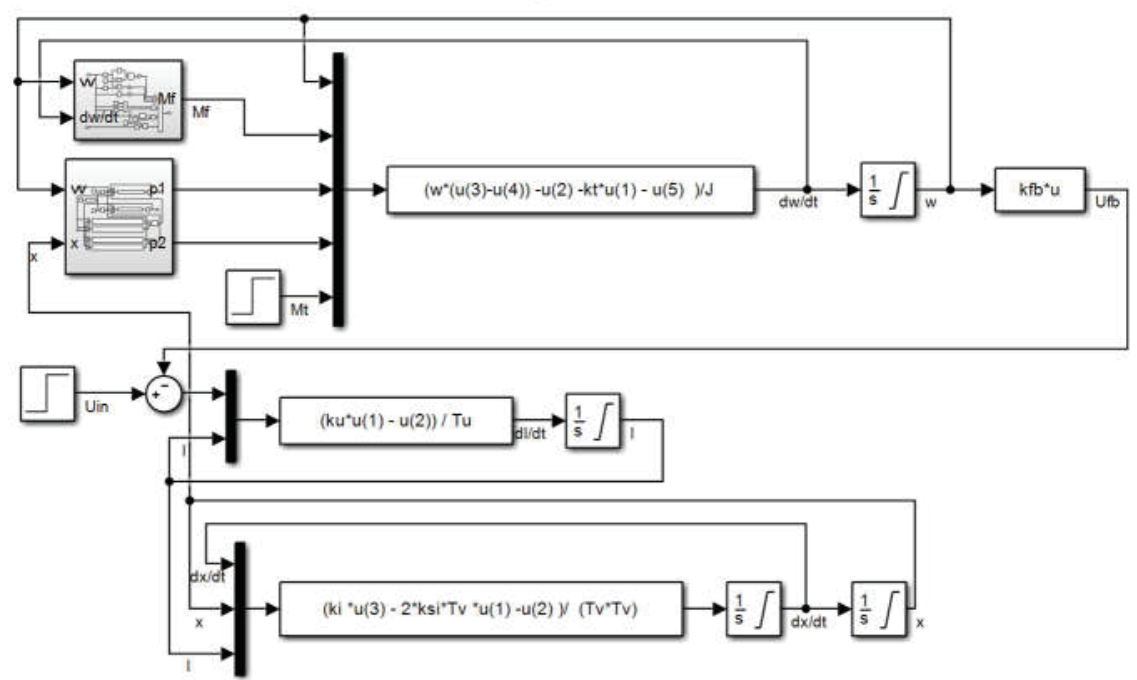

Fig. 3. Simulation model of the system. 


\section{Synthesis of fuzzy controller}

The block diagram of the automatic electrohydraulic system with the developed fuzzy selftuning PID controller, is shown in fig. 3. Input signals of the fuzzy controller are the system error e, its instantaneous change $\Delta \mathrm{e}$, and the output values are the parameters of the PID controller: $k$ - gain; $T_{i}$ - integration time constant and $T_{d}$ - differentiation time constant.

The logical table consists of a set of pre-compound logical rules of "if -then" type, which describe the control strategy and are obtained on the basis of expert knowledge. The output value $u$ in fuzzy control is determined by logical rules of the type:

\section{$R^{n}$ :if $e$ is $A_{i}$ and $\Delta e$ is $B_{i}$ then $k$ is $C_{i}$}

where $e, \Delta e, k, T_{i}$ and $T_{d}$ are linguistic variables of the corresponsive input-output quantities. Their universal sets are obtained from the ranges of variation of the corresponding quantities - $[-E, E],[-\Delta E, \Delta E],[-K, K],\left[-T_{i}, T_{i}\right]$ и $\left[-T_{d}, T_{d}\right] . A_{i}, B i$ and $\mathrm{C}_{\mathrm{i}}$ are fuzzy sets of the same quantities that are evenly distributed in these ranges.

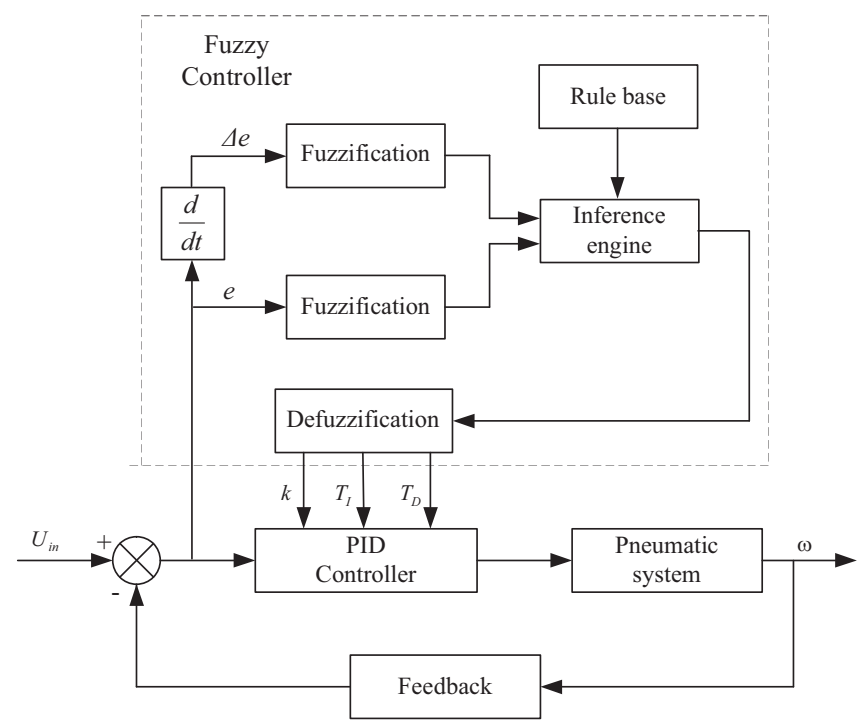

Fig. 4. The block diagram of the automatic electrohydraulic system with fuzzy self-tuning PID controller.

In the fig 5 and 6 is presented Simulink model of the automatic electrohydraulic system with fuzzy self-tuning PID controller.

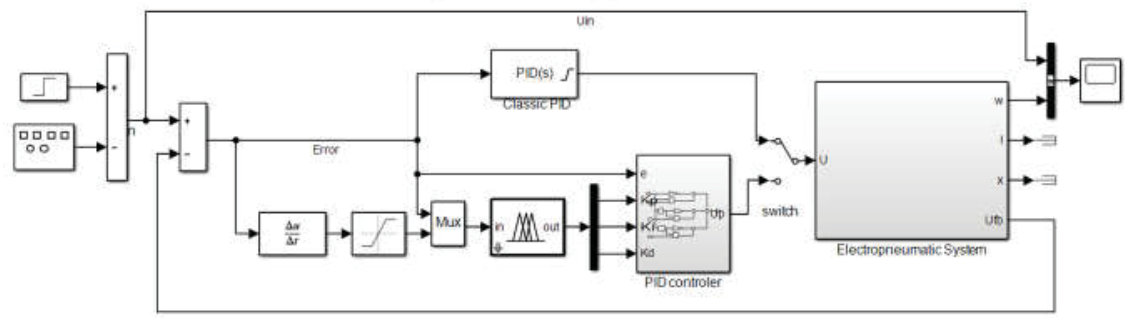

Fig. 5. Simulation model of the control system.

The fuzzy output mechanism in the logic block determines the decision for the parameters of the PID controller. The method of Mamdani's max-min composition, is used: 


$$
\mu_{i}=\max \left\{\min \left[\mu_{A j}, \mu_{B k}\right]\right\}
$$

where $\mu_{A j}$ and $\mu_{B k}$ are the levels of appurtenance.

The transition from fuzzy to real values of the initial values is realized in the defuzzification unit, using the method of the center of gravity in the form:

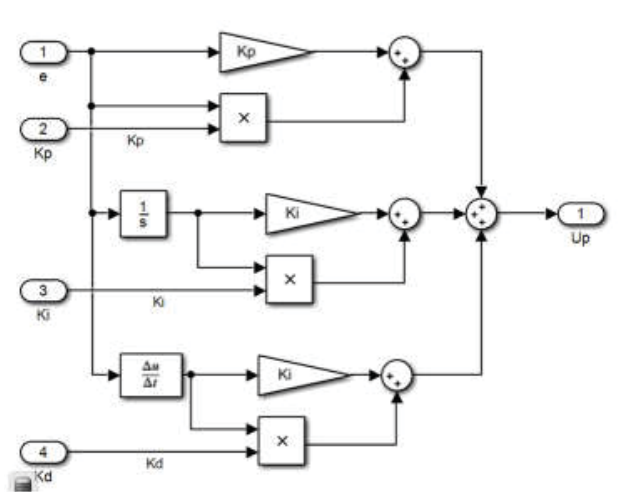

Fig. 6. Simulation model of the self-tuning PID controller.

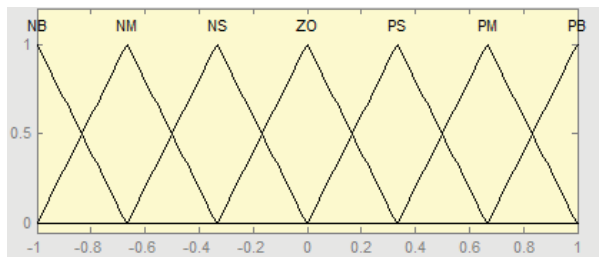

Fig. 7. Functions of membership of fuzzy sets of input quantities e and $\Delta \mathrm{e}$.

$$
k_{0}=\frac{\sum_{i=1}^{m} k_{i} \mu\left(k_{i}\right)}{\sum_{i=1}^{m} \mu\left(k_{i}\right)}
$$

where $k_{i}$ are the centers of the activated fuzzy sets, and $\mu\left(k_{i}\right)$ are the levels of appurtenance in them. Each input and output is described by a set of terms: Negative Long (NL) Negative Middle (NM), Negative Short (NS), Zero Rule (ZE), Positive Long (NL) Positive Middle (NM), Positive Short (NS). Fig. 7 and Fig. 8 presents the membership functions of the fuzzy sets of the inputoutput quantities $-e, \Delta e, k, T_{I}$ and $T_{D}$

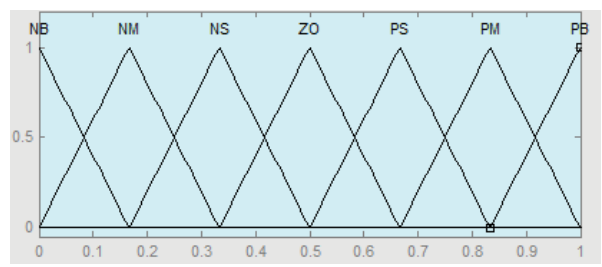

Fig. 8. Functions of membership of fuzzy sets of output quantities $k, T_{I}$ и $T_{D}$.

The rules formulating the logic of the fuzzy controller are presented in table. 1.

\begin{tabular}{|c|c|c|c|c|c|c|c|c|}
\hline \multirow{2}{*}{\multicolumn{2}{|c|}{$k / T_{I} / T_{D}$}} & \multicolumn{7}{|c|}{$\Delta e$} \\
\hline & & NB & NM & NS & $\mathrm{ZO}$ & PS & PM & PB \\
\hline \multirow{7}{*}{$e$} & NB & $\mathrm{PB} / \mathrm{PB} / \mathrm{NB}$ & $\mathrm{PB} / \mathrm{PB} / \mathrm{NB}$ & $\mathrm{PM} / \mathrm{PB} / \mathrm{NM}$ & $\mathrm{PM} / \mathrm{PB} / \mathrm{NM}$ & $\mathrm{PS} / \mathrm{PM} / \mathrm{NS}$ & $\mathrm{ZO} / \mathrm{PM} / \mathrm{ZO}$ & $\mathrm{ZO} / \mathrm{PS} / \mathrm{ZO}$ \\
\hline & NM & $\mathrm{PB} / \mathrm{PB} / \mathrm{NB}$ & $\mathrm{PB} / \mathrm{PB} / \mathrm{NB}$ & $\mathrm{PM} / \mathrm{PB} / \mathrm{NM}$ & $\mathrm{PS} / \mathrm{PM} / \mathrm{NS}$ & $\mathrm{PS} / \mathrm{PM} / \mathrm{NS}$ & $\mathrm{ZO} / \mathrm{PS} / \mathrm{ZO}$ & $\mathrm{NS} / \mathrm{ZO} / \mathrm{ZO}$ \\
\hline & NS & $\mathrm{PM} / \mathrm{ZO} / \mathrm{NB}$ & $\mathrm{PM} / \mathrm{PS} / \mathrm{NM}$ & $\mathrm{PM} / \mathrm{PM} / \mathrm{NS}$ & $\mathrm{PS} / \mathrm{PM} / \mathrm{NS}$ & $\mathrm{ZO} / \mathrm{PS} / \mathrm{ZO}$ & NS/PS/PS & $\mathrm{NS} / \mathrm{ZO} / \mathrm{PS}$ \\
\hline & $\mathbf{Z O}$ & $\mathrm{PM} / \mathrm{ZO} / \mathrm{NM}$ & $\mathrm{PM} / \mathrm{PS} / \mathrm{NM}$ & PS/PS/NS & $\mathrm{ZO} / \mathrm{NS} / \mathrm{ZO}$ & NS/PS/PS & NM/PS/PM & $\mathrm{NM} / \mathrm{ZO} / \mathrm{PM}$ \\
\hline & PS & $\mathrm{PS} / \mathrm{ZO} / \mathrm{NM}$ & $\mathrm{PS} / \mathrm{ZO} / \mathrm{NS}$ & $\mathrm{ZO} / \mathrm{ZO} / \mathrm{ZO}$ & $\mathrm{NS} / \mathrm{ZO} / \mathrm{PS}$ & NS/ZO/PS & $\mathrm{NM} / \mathrm{ZO} / \mathrm{PM}$ & $\mathrm{NM} / \mathrm{ZO} / \mathrm{PB}$ \\
\hline & PM & $\mathrm{PS} / \mathrm{NB} / \mathrm{ZO}$ & $\mathrm{ZO} / \mathrm{NS} / \mathrm{ZO}$ & NS/NS/PS & NM/NS/PM & NM/NS/PM & $\mathrm{NM} / \mathrm{NS} / \mathrm{PB}$ & $\mathrm{NB} / \mathrm{NB} / \mathrm{PB}$ \\
\hline & PB & $\mathrm{ZO} / \mathrm{NB} / \mathrm{ZO}$ & $\mathrm{ZO} / \mathrm{NM} / \mathrm{ZO}$ & NM/NM/PS & $\mathrm{NM} / \mathrm{NM} / \mathrm{PM}$ & $\mathrm{NM} / \mathrm{NS} / \mathrm{PM}$ & NB/NS/PB & $\mathrm{NB} / \mathrm{NB} / \mathrm{PB}$ \\
\hline
\end{tabular}

Table. 1 Rules for formulating a fuzzy controller

\section{Simulation results}

Based on the developed mathematical model, describing the operation of the electropneumatic tracking system from fig. 1 in dynamic mode, a corresponding analog model is constituted. For modeling and simulating the step responses, occurring in the automatic system, MATLAB Simulink is used. Fig. 9 and 10 shows the step responses in the 
automatic system with a single step input signal, using a classical PID controller and the synthesized fuzzy self-tuning PID controller, corresponding to Fig. 3.

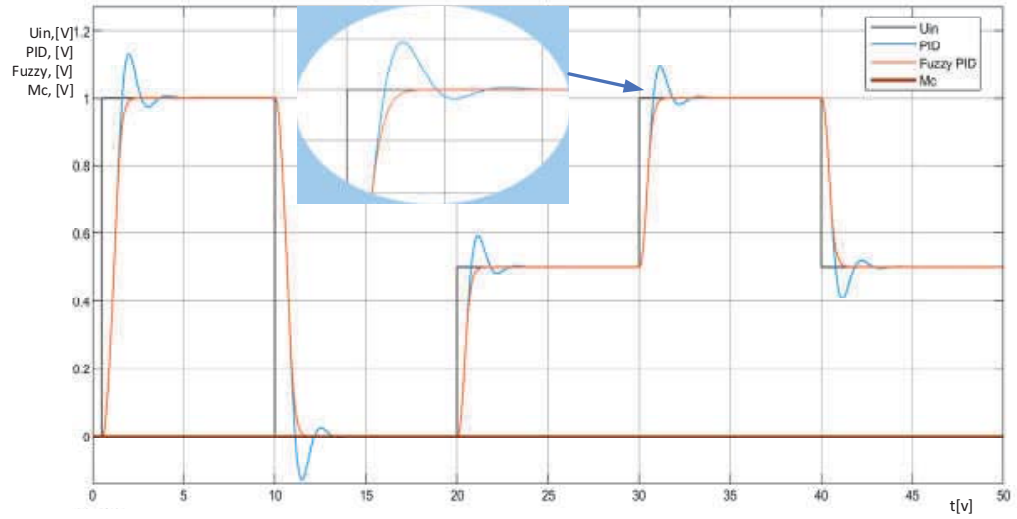

Fig. 9. Step response of the electropneumatic system of a change.

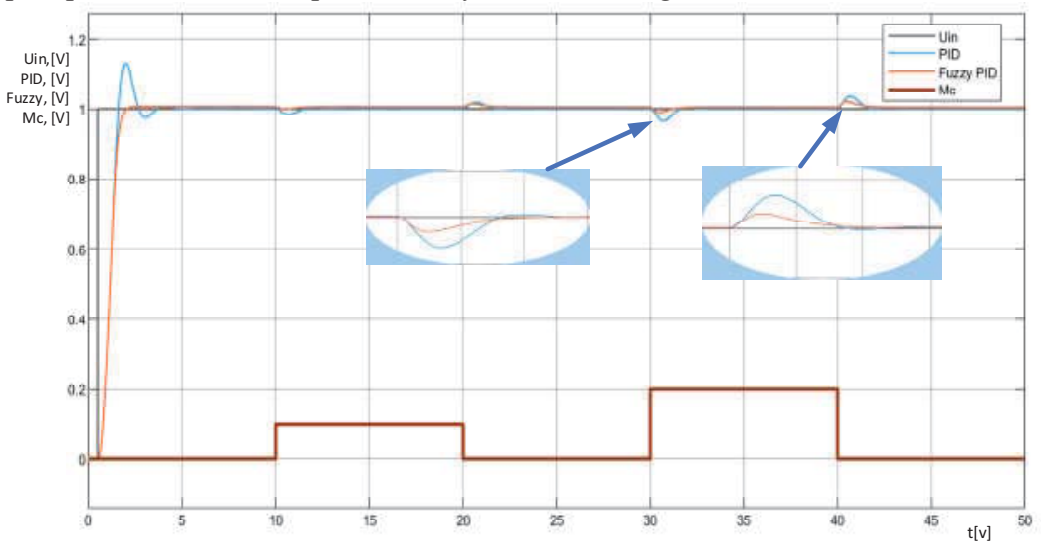

Fig. 10. Step response of the electropneumatic system at load change.

The obtained step responses for the automatic electropneumatic system from fig. 5 are gained at the following parameters of the controllers: using a classic PID controller $k=1.02, T_{I}=0.01 \mathrm{~s}$ и $T_{D}=0.25 \mathrm{~s}$; using a fuzzy auto-PID controller, as ranges of change are $-0<k \leq 2,0.1 s \leq T_{I} \leq 8 s$ и $0 \leq T_{D} \leq 0.8 s$. the graphs from fig. 7 and 8 are obtained at the following parameters of the adaptive PID controller $k=1.82, T_{I}=0.01 \mathrm{~s} \mathrm{и} T_{D}=0.46 \mathrm{~s}$.

\section{Conclusions}

The developed mathematical model in the paper can be used to study the dynamic processes in an automatic electropneumatic tracking system with a rotary actuator from Fig. 1, using a classic PID or a fuzzy self-tuning PID controller with variable coefficients. The comparative analysis of the transitional processes in the control systems with linear discontinuous controllers and fuzzy controllers - their analogues, show the applicability of Fuzzy PID controllers in solving problems about how to control of Electropneumatic System. The parameters of the fuzzy controllers are determined by the parameters of the corresponding linear continuous controllers and the corresponding optimization procedure. Right away with the initial setup of the fuzzy controllers, a good quality of the transitional processes in system is obtained. By following the methodology, for two or at most three iterations, the final values of the parameters for setting the fuzzy controllers are obtained. The analyzed fuzzy 
regulators provide better robustness for the systems than the corresponding linear continuous controllers. The use of the fuzzy controller leads to the improvement of the quality of the step response - the process performs according to an aperiodic law and its duration is significantly decreased. The adaptive architecture of the Fuzzy PID controller provides a wide operating range of adjustment when changing the setpoint and disturbances.

\section{REFERENCES}

1. A. AL-Assady, A. Hassan, M. Talib, J. AL-Khafaji, Design and Analysis of ElectroHydraulic Servo System for Speed Control of Hydraulic Motor, Jurnal of Engineering, Nomber 5, Volume 19, May, Baghdad (2013)

2. A. Basmenj, A. Sakhavati, PID Controller Design for Position Control of Electrohydraulic Actuators Using Imperialist Competitive Algorithm, Indian J. Sci. Res., 1(1), pp. 775-779 (2014)

3. E. Detiček, U. Župer, An Intelligent Electro-Hydraulic Servo Drive, Journal if Mechanical Engineering 57 Positioning, Slovenia (2011)

4. C. Harris, C. Moore, M. Brown, Intelligent control - Aspects of Fuzzy Logic and Neural Nets, World Scientific, London (1994)

5. J. Hassan, S.Y. Ibrahim, An Experimental Study Into the Effect of Temperature and Pressure on the Hydraulic System, Eng. \& Tech. Jurnal, Vol.27, No.14, Mechanical Engineering Department, University of Technology - Baghdad (2009)

6. M. Jovanovic, Nonlinear Control of an Electrohydraulic Velocity Servosystem, Proceedings of the American Control Conference Anchorage, AK 2012, May 8-10, (2012)

7. E. Mamdani, Application of fuzzy algorithms for control of simple dynamic plant, Proceedings IEEE, 121 , N0.12 (1974)

8. K. Ormandzhiev, Transient Processes in Electro-Hydraulic Follow-up System with Long Pressure Pipelines, 30th SEM HIPNEF 2006, May 24 - 26, Vrnjacka Banja, , pp. 123 - 130 (2006)

9. M. Petrov, I. Ganchev, A. Taneva. Fuzzy PID Control of Nonlinear Plants, Proceedings of the IEEE International Symposium on "Intelligent Systems", Varna, Bulgaria, 10 13 September, 2002, IEEE Catalog Number 02EX499, ISBN 0-7803-7601-3, Vol. 1, pp. $30-35$ (2002)

10. M. Shafiabadi, M. Jahanshahi, A. Bidaki, Feedback Error Learning using Laguerrebased Controller to Control the Velocity of an Electro Hydraulic Servo System, Australian Journal of Basic and Applied Sciences, 6(10), pp. 222-230, (2012)

11. M. Xu, B. Jin, G. Chen, J. Ni, Speed-Control of Energy Regulation Based Varible-Speed Electrohydraulic Drive, Strojniski vestnik - Journal of Mechanical Enginneering 59,78, pp. 433-442 (2013)

12. J. G. Ziegler, N. B. Nichols, The optimum Setting the odds Automatic Controllers, ASME, Rochester, N.Y. (1942)

13. A. Leonenkoff, Fuzzy Simulation in MATLAB and fuzzyTech, BHV Peterburg, ISBN: 594157-087-2, Language: Russian (2003)

14. D. Zeng, Y. Zheng, W. Luo, Y. Hu, Q Cui, C. Peng ,Research on Improved AutoTuning of a PID Controller Based on Phase Angle Margin, Energies, 12, 1704; doi:10.3390/en12091704 (2019) 